\title{
Streptomyces araujoniae Produces a Multiantibiotic Complex with Ionophoric Properties to Control Botrytis cinerea
}

\author{
Leonardo José Silva, Eduardo José Crevelin, Wallace Rafael Souza, \\ Luiz Alberto Beraldo Moraes, Itamar Soares Melo, and Tiago Domingues Zucchi
}

First, third, fifth, and sixth authors: Laboratório de Microbiologia Ambiental, EMBRAPA, Jaguariúna, Brazil; and second and fourth authors: Laboratório de Espectrometria de Massa Aplicado à Química de Produtos Naturais, FFCLRP/USP, Ribeirão Preto, Brazil. Current address of sixth author: Agrivalle, Pouso Alegre, Brazil.

Accepted for publication 7 June 2014.

\begin{abstract}
Silva, L. J., Crevelin, E. J., Souza, W. R., Moraes, L. A. B., Melo, I. S., and Zucchi, T. D. 2014. Streptomyces araujoniae produces a multiantibiotic complex with ionophoric properties to control Botrytis cinerea. Phytopathology 104:1298-1305.

A recently described actinomycete species (Streptomyces araujoniae ASBV-1 ${ }^{\mathrm{T}}$ ) is effective against many phytopathogenic fungi. In this study, we evaluated the capacity of this species to inhibit Botrytis cinerea development in strawberry pseudofruit, and we identified the chemical structures of its bioactive compounds. An ethyl acetate crude extract $(0.1$ $\mathrm{mg} \mathrm{ml} \mathrm{l}^{-1}$ ) of ASBV-1 ${ }^{\mathrm{T}}$ fermentation broth completely inhibited fungus growth in strawberry pseudofruit under storage conditions. The crude

tography; the active fraction was further evaluated by tandem mass spectrometry. ASBV- $1^{\mathrm{T}}$ produced a multiantibiotic complex with ionophoric properties. This complex contained members of the macrotetralides class (including monactin, dinactin, trinactin, and tetranactin) and the cyclodepsipeptide valinomycin, all of which were active against B. cinerea. Furthermore, the addition of $2 \mathrm{mM} \mathrm{MgSO}_{4}$ and $1 \mathrm{mM} \mathrm{ZnSO}_{4}$ enhanced macrotetralide and valinomycin production, respectively, in the culture broth. These compounds are considered to be the main active molecules that $S$. araujoniae produces to control B. cinerea. Their low to moderate toxicity to humans and the environment justifies the application of ASBV $-1^{\mathrm{T}}$ in biological control programs that aim to mitigate the damage caused by this phytopathogen.
\end{abstract} extract was fractionated by preparative high-performance liquid chroma-
Botrytis cinerea or "gray mold", is a cosmopolitan phytopathogen that damages diverse agricultural crops and poses a special threat to strawberry culture. Infection usually starts in the field; however, greater losses occur during the postharvest period (16), and the pseudofruit become unmarketable after only a few storage days. Generally, the use of synthetic fungicides during preharvest helps to control this phytopathogen. However, resistant $B$. cinerea strains have emerged due to the indiscriminate use of fungicides (32), which have negatively affected the environment, nontarget organisms, and human health (14), apart from reducing product quality and restricting the consumer market (10). The general public has become increasingly aware of chemical pesticides (5) and has called for more "eco-friendly" methods to mitigate the damages caused by agricultural pests (6). In this context, microorganisms have long served as a reliable source of compounds to control agricultural pests (9). These organisms can either be directly introduced in the crop field or their byproducts can be obtained for use in pest control.

Biocontrol agents offer some natural advantages over fungicides, mainly due to the many modes of action by which they inhibit the development of phytopathogenic fungi. These multiple modes of action reduce the selection of resistant strains and include competition for space or nutrients, mycoparasitism, plantinduced resistance, promotion of plant growth, and production of lytic enzymes and secondary metabolites (mainly antibiotics).

Corresponding author: T. D. Zucchi; E-mail address: tiago_zucchi@ hotmail.com

* The $\boldsymbol{e}$-Xtra logo stands for "electronic extra" and indicates that the online version contains five supplementary figures and one supplementary table.

http://dx.doi.org/10.1094/PHYTO-11-13-0327-R

(C) 2014 The American Phytopathological Society
Moreover, the incorporation of biocontrol agents along with fungicides in integrated pest management programs diminishes the collateral effects inherent in chemical control (12). Among the biocontrol agents, actinomycetes have been extensively exploited due to their ability to produce biocompounds (antibiotics) that are active against phytopathogens. Indeed, this particular bacterial group is responsible for producing $>52 \%$ of all known antibiotics, of which $75 \%$ are produced by members of the genus Streptomyces (3). Nevertheless, antibiotic production is often the main mode of action by which actinomycetes suppress phytopathogen development. Despite the vast amount of literature on the use of biocontrol agents to inhibit gray mold development, only a few biological products such as Serenade (AgraQuest Inc., Davis, CA) and TRICHODEX 20P (Makhteshim Ltd., Be'er Sheva, Israel) have reached the market (22), and none of them are based on actinomycete strains.

In our search for bacterial biocontrol agents, we have isolated and described a novel streptomycete species (isolate ASBV-1 ${ }^{\mathrm{T}}$ ), Streptomyces araujoniae (28), and demonstrated bioactive potential against several phytopathogenic fungi, including $B$. cinerea. In this article, we evaluated whether ASBV-1 ${ }^{\mathrm{T}}$ could control $B$. cinerea development in strawberry pseudofruit under storage conditions; we also determined the chemical structures of the bioactive compounds produced by ASBV $-1^{\mathrm{T}}$ by mass spectrometry.

\section{MATERIALS AND METHODS}

Organisms, maintenance, and cultural conditions. The $S$. araujoniae $\mathrm{ASBV}-1^{\mathrm{T}}$ strain and the $B$. cinerea CCMA 1122 wild type were obtained from Coleção de Microorganismos de Importância Agrícola e Ambiental (CCMA, EMBRAPA, Brazil). The strains were maintained on potato-dextrose agar (PDA) plates (2) at $4^{\circ} \mathrm{C}$. 
Extraction of secondary metabolites from isolate ASBV $-1^{\text {T }}$ cultures. The ASBV $-1^{\mathrm{T}}$ isolate was inoculated in 10 liters of potato-dextrose (PD) broth and incubated on a shaker (180 rpm) for 10 days at $28^{\circ} \mathrm{C}$. The secondary metabolites were extracted according to Canova et al. (4), using ethyl acetate (EtOAc) as solvent. EtOAc was then evaporated to dryness in a rotary evaporator (R-250/B-490; Büchi, Schweiz) at $45^{\circ} \mathrm{C}$, yielding $320 \mathrm{mg}$ of the crude extract. A portion of this extract was dissolved in dimethyl sulfoxide (DMSO) to a final concentration of $1.0 \mathrm{mg} \mathrm{ml}^{-1}$ and used in the in vitro and in vivo bioassays. The other portion of the crude extract was used to chemically characterize the compounds.

In vitro and in vivo bioassays. Conidia germination of B. cinerea CCMA 1122 was evaluated in vitro. Suspensions of $1 \times 10^{8}$ conidia $\mathrm{ml}^{-1}$ were inoculated in $10 \mathrm{ml}$ of $\mathrm{PD}$ broth amended with ASBV $-1^{\mathrm{T}}$ crude extract $\left(0.1,0.5\right.$, and $\left.1.0 \mathrm{mg} \mathrm{ml}^{-1}\right)$ and incubated at $15^{\circ} \mathrm{C}$. The commercial fungicide Cercobin 500 SC $\left(0.1,1.0\right.$, and $\left.5.0 \mathrm{mg} \mathrm{m}^{-1}\right)$ was used as a positive control. Treatments without the crude extract or the fungicide were also included in each experiment as negative controls. Every $4 \mathrm{~h}, 10-\mu \mathrm{l}$ aliquots were extracted from each treatment vial, and conidia germination was observed under a light microscope. Germ tubes twice as long as the conidia were scored as positive for germination. The experiment was conducted in triplicate. In total, 100 conidia were counted per replication, and the germinated conidia were scored. After the germination pattern was obtained, the lethal concentration $\left(\mathrm{LC}_{50}\right)$ was calculated using SAS software.

The ASBV $-1^{\mathrm{T}}$ crude extract was further evaluated in vivo under storage conditions $\left(15^{\circ} \mathrm{C}\right)$ using freshly picked commercial strawberry fruit ('Oso Grande'). The pseudofruit were surface sterilized with $70 \%$ alcohol, $20 \%$ sodium hypochlorite, and sterilized distilled water (twice), immersed in each stage for $30 \mathrm{~s}$, as described previously (36), prior to being used in the treatments. DMSO was used as the crude extract solvent. Treatment consisted of immersing the pseudofruit in an ASBV-1 $1^{\mathrm{T}}$ cell suspension $(1 \times$ $10^{6}$ cells $\mathrm{ml}^{-1}$ ) or $\mathrm{ASBV}-1^{\mathrm{T}}$ crude extract solution at different concentrations $\left(0.01,0.1\right.$, and $\left.1.0 \mathrm{mg} \mathrm{ml}^{-1}\right)$ immediately before applying the conidia suspension $\left(1 \times 10^{8}\right.$ conidia $\left.\mathrm{ml}^{-1}\right)$ of the phytopathogen. Pseudofruit in natura were employed as negative controls. Treatments without the crude extract or with the crude extract containing only (i) the isolate $\mathrm{ASBV}-1^{\mathrm{T}}$, (ii) the phytopathogen, or (iii) DMSO (after surface sterilization) were also included in this bioassay. The experiments were performed in triplicate, and six pseudofruit were used for each treatment. Statistical analysis of the in vitro and in vivo experiments was carried out using ASSISTAT software (version 7.7) (27).

High-performance liquid chromatography and thin-layer chromatography analysis. Preparative high-performance liquid chromatography (HPLC) was accomplished following the methods of Crevelin et al. (8) using a $\mathrm{C}_{18}$ Shim-Pack Shimadzu column $(250 \times 20 \mathrm{~mm}, 5 \mu \mathrm{m})$. The mobile phase consisted of $\mathrm{H}_{2} \mathrm{O}$ (solvent A) and methanol $(\mathrm{MeOH}$; solvent B). The elution program included a 40-min gradient of 20 to $100 \% \mathrm{MeOH}$ at a flow rate of $15.0 \mathrm{ml} \mathrm{min}$. . HPLC progress was monitored at 270 and $340 \mathrm{~nm}$. The fractions were assayed against $B$. cinerea in vitro to determine their inhibitory activity, as described previously. Filter discs ( $0.5 \mathrm{~mm}$ in diameter) were used to apply $10 \mu \mathrm{l}$ of each fraction. Thin-layer chromatography (TLC) was performed using a solvent system of 2:8 hexane/EtOAc ( $\mathrm{vol} / \mathrm{vol}$ ) by applying the sample to the start line of a $0.3-\mathrm{mm}(10 \times 5 \mathrm{~cm})$ silica gel 60 plate (Merck, Whitehouse Station, NJ). The plates were visualized under ultraviolet light at 254 and $364 \mathrm{~nm}$.

Mass spectrometry analysis. Electrospray ionization mass spectrometry (ESI-MS) experiments with the ASBV-1 ${ }^{\mathrm{T}}$ crude extract and bioactive fractions were conducted on a Waters ACQUITY UPLC $H$-Class system coupled to the Xevo TQ-S tandem quadrupole (Waters Corporation, Milford, MA) mass spectrometer with a Z-spray source operating in positive mode. The operating parameters of the instrument were optimized as follows: capillary voltage, $3.2 \mathrm{kV}$; cone voltage, $40 \mathrm{~V}$; Z-spray source temperature, $150^{\circ} \mathrm{C}$; desolvation temperature $\left(\mathrm{N}_{2}\right), 300^{\circ} \mathrm{C}$; and desolvation gas flow, 700 liters $\mathrm{h}^{-1}$ (mass range of $\mathrm{m} / \mathrm{z}, 150$ to $1,300)$. Tandem mass spectrometry (MS/MS) was performed on the isolated precursor ions by collision-induced dissociation (CID) with a collision energy ranging from 10 to $50 \mathrm{eV}$ and Argon (Ar) as the collision gas. The crude extract was analyzed by ultra-high-performance liquid chromatography mass spectrometry (UPLC-MS) in the full scan mode by injecting $3 \mu \mathrm{l}$ of the sample into a Waters ACQUITY-BEH $\mathrm{C}_{18}$ column $(2.1 \times 50 \mathrm{~mm}$, $1.7 \mu \mathrm{m})$; the mobile phase consisted of $\mathrm{H}_{2} \mathrm{O}+10 \mathrm{mM}$ ammonium acetate $\left(\mathrm{CH}_{3} \mathrm{COO}^{-} \mathrm{NH}_{4}{ }^{+}\right)$(solvent A) and $\mathrm{MeOH}$ (solvent B). The elution program involved a 5-min gradient of 75 to $97 \% \mathrm{MeOH}$ followed by a 5-min elution with $97 \% \mathrm{MeOH}$ at a flow rate of $0.3 \mathrm{ml} \mathrm{min}^{-1}$. The UPLC-MS experiments were conducted in the selective ion monitoring (SIM) mode using a Kinetex $\mathrm{C}_{18}$ column $(2.1 \times 100 \mathrm{~mm}, 1.7 \mu \mathrm{m})$ from Phenomenex within the same mobile phase conditions mentioned above. The bioactive fractions were further analyzed by high-resolution electrospray ionization mass spectrometry (HRESIMS) on an LTQ-FT-Ultra mass spectrometer (Thermo Scientific, Waltham, MA) using a nanospray source operating in the positive mode. The analysis was carried out at a source voltage of $4.0 \mathrm{kV}$ and a capillary voltage of $50 \mathrm{~V}$, with a sheath gas flow rate of 0.09 liter $\mathrm{min}^{-1}$ and a capillary temperature of $270^{\circ} \mathrm{C}$ (mass range of $\mathrm{m} / \mathrm{z}, 500$ to 1,500 ).

Influence of inorganic salts on the production of bioactive compounds and biomass. Strain ASBV- $1^{\mathrm{T}}$ was grown in $50 \mathrm{ml}$ of PD broth under constant agitation $(180 \mathrm{rpm})$ at $28^{\circ} \mathrm{C}$ for 20 days. The kinetics of bioactive compound production was evaluated by sampling 1-ml aliquots at intervals of $0,1,3,5,7$, 10,15 , and 20 days. The secondary metabolites of interest were extracted from each sample and analyzed by UPLC-MS in the SIM mode. The compound production curves were built by relating the area intensity ratio to the culture period. Thereafter, a second experiment was performed: the isolate was inoculated in $50 \mathrm{ml}$ of PD broth supplemented with $\mathrm{CuSO}_{4}, \mathrm{FeSO}_{4}, \mathrm{MgSO}_{4}$, $\mathrm{MnSO}_{4}$, and $\mathrm{ZnSO}_{4}$ at different concentrations (1-5 mM), to evaluate how the inorganic salts affected bioactive compound production. The isolate was incubated for 5 days under the same conditions described previously; compound production was evaluated by UPLC-MS in the SIM mode. At the end of the experiment, the cultures were centrifuged (7,000 rpm, $20 \mathrm{~min})$ and the pellets were freeze dried before determining the biomass production in the presence of inorganic salts.

\section{RESULTS}

In vitro and in vivo bioassays. Cercobin $500 \mathrm{SC}$ and the crude extract of the ASBV- $1^{\mathrm{T}}$ isolate differed from the control with respect to number of germinated conidia (Table 1). These differences could be observed at the earliest stages of the in vitro experiment (after $4 \mathrm{~h}$ of incubation) and persisted until the last point assayed $(16 \mathrm{~h})$. It can be seen from Table 1 that, after $16 \mathrm{~h}$ of incubation, the ASBV- $1^{\mathrm{T}}$ crude extract and the commercial fungicide presented similar levels of activity (Table 1); at $1.0 \mathrm{mg}$ $\mathrm{ml}^{-1}$, conidia germination was inhibited by 71.8 and $69.9 \%$ by Cercobin $500 \mathrm{SC}$ and $\mathrm{ASBV}-1^{\mathrm{T}}$ crude extract, respectively, compared with the control. The crude extract efficiency in controlling $B$. cinerea germination diminished at the lower tested dose (only 9.5\% conidia inhibition), although the efficiency did not differ from that of Cercobin $500 \mathrm{SC}$ at $0.1 \mathrm{mg} \mathrm{ml}^{-1}$. Finally, Cercobin $500 \mathrm{SC}$ had a slightly lower $\mathrm{LC}_{50}\left(0.123\right.$ versus $\left.0.262 \mathrm{mg} \mathrm{ml}^{-1}\right)$ than the crude extract.

The commercially grown strawberry fruit used in our in vivo bioassay were naturally infected with a fungus but surface sterilization prior to biocontrol treatment and inoculation with $B$. cinerea 
effectively eliminated the fungus (Fig. 1A and B). Inoculation with $B$. cinerea CCMA 1122 alone resulted in considerable fungal infection on the sterilized fruit (Fig. 1C) whereas inoculation with $S$. araujoniae ASBV $-1^{\mathrm{T}}$ alone did not cause any damage to the pseudofruit (Fig. 1D). DMSO, which was used as the solvent for application of crude extracts in the biocontrol treatment, did not affect the growth of the inoculated pathogen (Fig. 1E). Use of strain ASBV $-1^{\mathrm{T}}$ as a biocontrol agent did not inhibit $B$. cinerea growth on the pseudofruit (Fig. 1F); however, ASBV- ${ }^{\mathrm{T}}$ byproducts (crude extract at 1.0 and $0.1 \mathrm{mg} \mathrm{ml}^{-1}$ ) were able to control the fungal phytopathogen (Fig. $1 \mathrm{G}$ and $\mathrm{H}$ ). Indeed, at the highest tested concentration $\left(1.0 \mathrm{mg} \mathrm{ml}^{-1}\right)$, the pseudofruit infection was reduced to $11.7 \%$ and, at the lowest tested dose $\left(0.01 \mathrm{mg} \mathrm{ml}^{-1}\right)$, the average number of infected pseudofruit decreased by $26 \%$. However, this infection rate did not differ significantly from that observed in the positive control.

Bioassay-guided fractionation and structural identification by MS. We used preparative HPLC with UV-vis detection to fractionate the bioactive ASBV- $1^{\mathrm{T}}$ crude extract, which yielded a total of 53 fractions ( $\approx 10 \mathrm{ml}$ each). The in vitro bioassay demonstrated that fractions 42 and 43 inhibited $B$. cinerea conidia germination (Supplementary Figure 1); thus, we selected these fractions to conduct further structural characterization.
A comparison using TLC revealed that the chemical profiles of fractions 42 and 43 were nearly identical; thus, we combined the fractions (Fr ASBV-1, $22 \mathrm{mg}$ ) and analyzed them by ESI-MS in the full-scan mode by flow injection into the UPLC-MS, bypassing column chromatography. The mass spectrum (Fig. 2) displayed two major groups of peaks, from $\mathrm{m} / \mathrm{z} 750$ to 850 and from $\mathrm{m} / \mathrm{z}, 1,100$ to 1,300 (Fig. 2). The first group of peaks had high relative intensity, and the difference between the peaks was equal to 14 mass units. This difference indicated the presence of homologous compounds belonging to the same class of chemical compounds. Additionally, the extracted ion chromatograms (Fig. 3) obtained via UPLC-MS of Fr ASBV-1 confirmed that the applied methodology efficiently separated the target compounds. The ions of $\mathrm{m} / \mathrm{z} 768,782,796$, and 810 displayed similar chemical profiles, with small differences in their retention times, whereas the ion of $\mathrm{m} / \mathrm{z} 1,128$ exhibited a higher retention time, indication that it is a more apolar compound. Compounds in the range of $m / z, 750$ to 850 formed adducts with $\mathrm{H}^{+}(\mathrm{m} / z, 751, \mathrm{~m} / z$ $765, m / z, 779$, and $m / z$ 793), $\mathrm{NH}_{4}{ }^{+}(\mathrm{m} / z \mathrm{z} 768, \mathrm{~m} / \mathrm{z} 782, \mathrm{~m} / \mathrm{z} 796$, and $m / z$ 810), $\mathrm{Na}^{+}(m / z, 773, m / z, 787, m / z, 801$, and $m / z, 815)$, and $\mathrm{K}^{+}$ $(\mathrm{m} / \mathrm{z}, 789, \mathrm{~m} / \mathrm{z}, 803, \mathrm{~m} / \mathrm{z} 817$, and $\mathrm{m} / \mathrm{z}, 831)$. These peaks differed by 5,16 , and 22 mass units from each other, which might be due to the mass differences between the ions $\left(\mathrm{M}+\mathrm{NH}_{4}\right)^{+}$and $[\mathrm{M}+\mathrm{Na}]^{+}$,

TABLE 1. Number of germinated Botrytis cinerea CCMA 1122 conidia after treatment with Cercobin 500 SC and ethyl acetate crude extract of Streptomyces ASBV-1 ${ }^{\text {Tz }}$

\begin{tabular}{|c|c|c|c|c|c|c|c|}
\hline \multirow[b]{2}{*}{ Time (h) } & \multicolumn{3}{|c|}{ Cercobin $\left(\mathrm{mg} \mathrm{ml}^{-1}\right)$} & \multicolumn{3}{|c|}{ Crude extract $\left(\mathrm{mg} \mathrm{ml}^{-1}\right)$} & \multirow[b]{2}{*}{ Control } \\
\hline & 0.1 & 1.0 & 5.0 & 0.1 & 0.5 & 1.0 & \\
\hline 4 & $2.0 \mathrm{~b}^{*}$ & $1.0 \mathrm{~b}$ & $1.7 \mathrm{~b}$ & $1.0 \mathrm{~b}$ & $1.0 \mathrm{~b}$ & $0.3 \mathrm{~b}$ & $6.7 \mathrm{a}$ \\
\hline 8 & $19.0 \mathrm{ab}$ & $10.7 b c$ & $8.0 \mathrm{bc}$ & $11.0 \mathrm{bc}$ & $8.3 b c$ & $1.7 \mathrm{c}$ & $25.7 \mathrm{a}$ \\
\hline 16 & $38.3 \mathrm{bc}$ & $20.7 \mathrm{~d}$ & $20.0 \mathrm{~d}$ & $50.3 \mathrm{~b}$ & $26.3 \mathrm{~cd}$ & $22.0 \mathrm{~cd}$ & $73.3 \mathrm{a}$ \\
\hline
\end{tabular}

${ }^{\mathrm{z}}$ Asterisk (*) indicates data that represent the average number of germinated conidia out of a total of 100 conidia observed for each of three replicates. The same letter in the row indicates nonsignificant difference by Tukey test at $5 \%(P<0.05)$.

\section{Day 5}

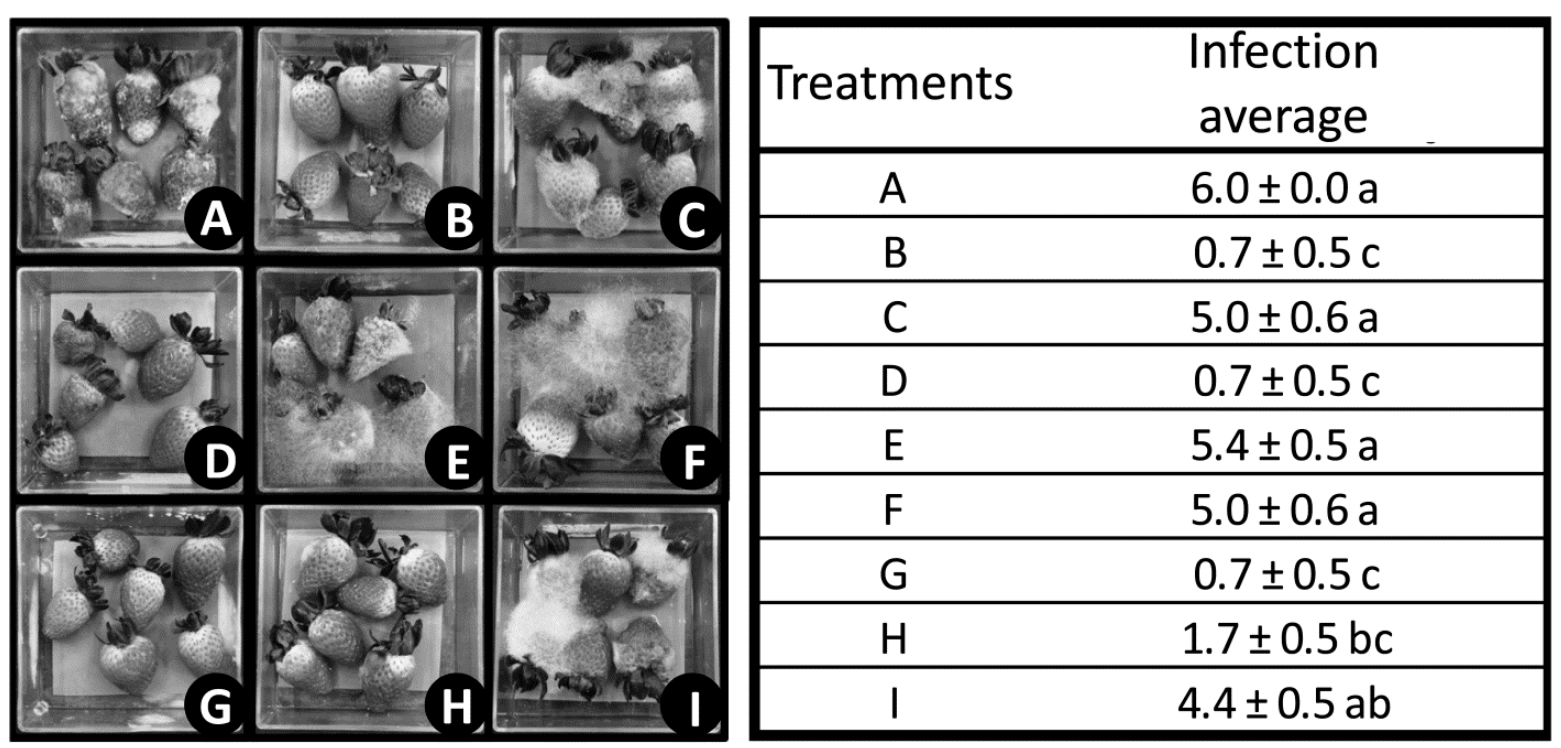

Fig. 1. In vivo bioassay of the efficacy of Streptomyces araujoniae ASBV-1 ${ }^{\mathrm{T}}$ (strain and its byproducts) in the control of Botrytis cinerea on strawberry pseudofruit as revealed by the average number of infected pseudofruit 5 days after treatment and inoculation with the fungal pathogen. A, Naturally infected pseudofruit that were not surface sterilized, not treated, and not inoculated with $B$. cinerea; $\mathbf{B}$, surface-sterilized pseudofruit that remained untreated and uninoculated; $\mathbf{C}$ to I, all pseudofruit were surface sterilized prior to the following treatment or inoculation: C, inoculation with $B$. cinerea only; D, inoculation of ASBV-1 ${ }^{\mathrm{T}}$ only; E, inoculation with $B$. cinerea followed by application of DMSO; $\mathbf{F}$, inoculation with strain ASBV-1 ${ }^{\mathrm{T}}$ immediately prior to inoculation with $B$. cinerea; $\mathbf{G}$ to I, treatment with ASBV $-1^{\mathrm{T}}$ crude extract (dimethyl sulfoxide at $1.0,0.1$, and $0.01 \mathrm{mg} \mathrm{ml}^{-1}$, respectively) prior to inoculation with $B$. cinerea. Right panel: data represent the average of the number of infected pseudofruit out of a total of six pseudofruit per three replicate samples. The same lowercase letter following values indicates nonsignificant difference by Tukey test at $5 \%(P<0.05)$. 
the ions $[\mathrm{M}+\mathrm{Na}]^{+}$and $[\mathrm{M}+\mathrm{K}]^{+}$, and the ions $[\mathrm{M}+\mathrm{Na}]^{+}$and $[\mathrm{M}+\mathrm{H}]^{+}$, respectively.

We selected the precursor ions of $\mathrm{m} / z, 787[\mathrm{M}+\mathrm{Na}]^{+}$and 815 $[\mathrm{M}+\mathrm{Na}]^{+}$to identify its chemical structures by MS/MS. These adducts revealed successive neutral losses of 184 and $198 \mathrm{u}$ (Fig. 4), similar to what was observed for all signals in the range of $\mathrm{m} / \mathrm{z}$ 750 to 850 . According to Vincenti et al. (31), the fragmentation patterns of these ions were typical of the polyether ionophore

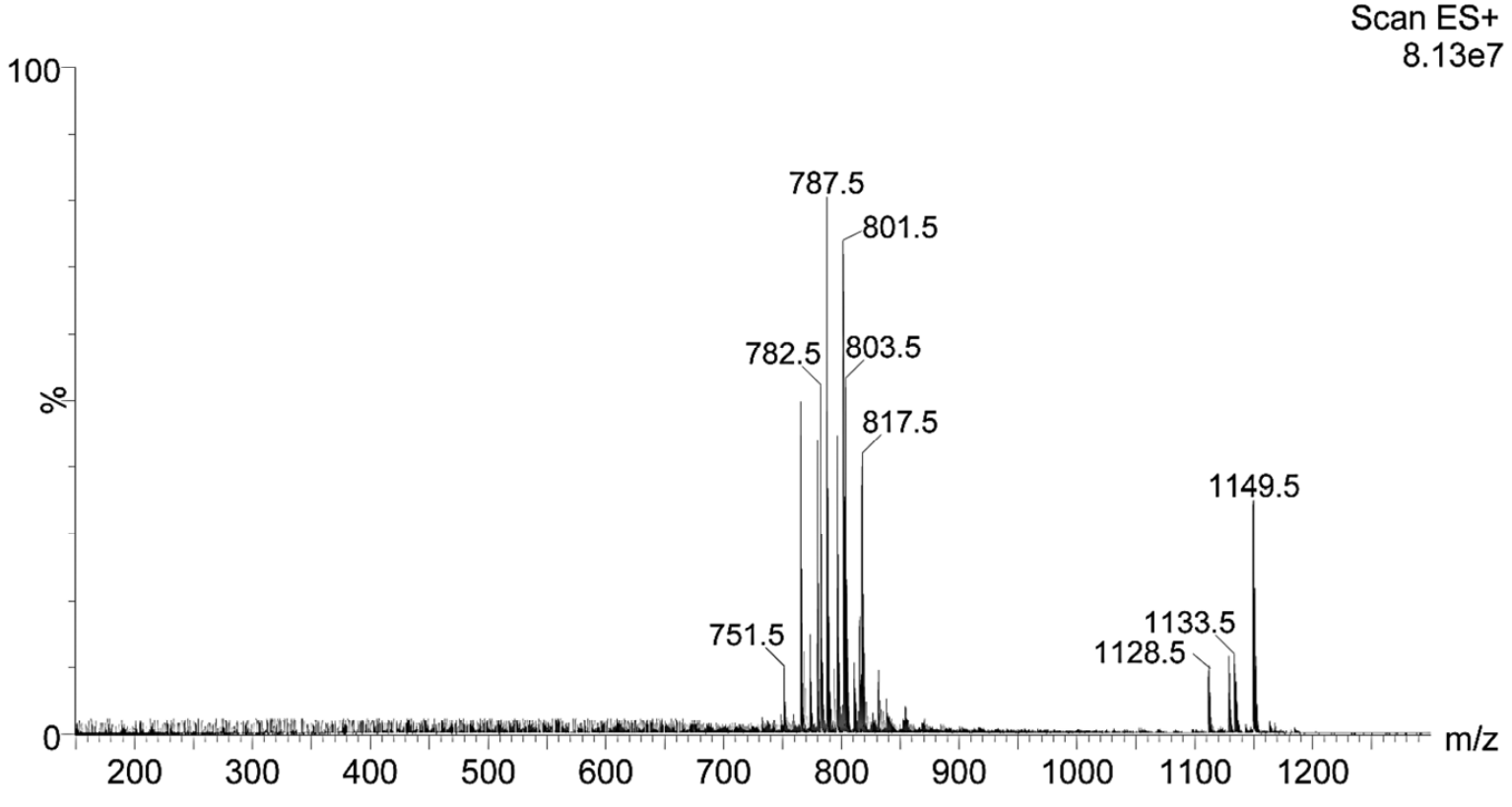

Fig. 2. Full-scan mass spectrum of $\mathrm{ASBV}-1^{\mathrm{T}}$ bioactive fraction.

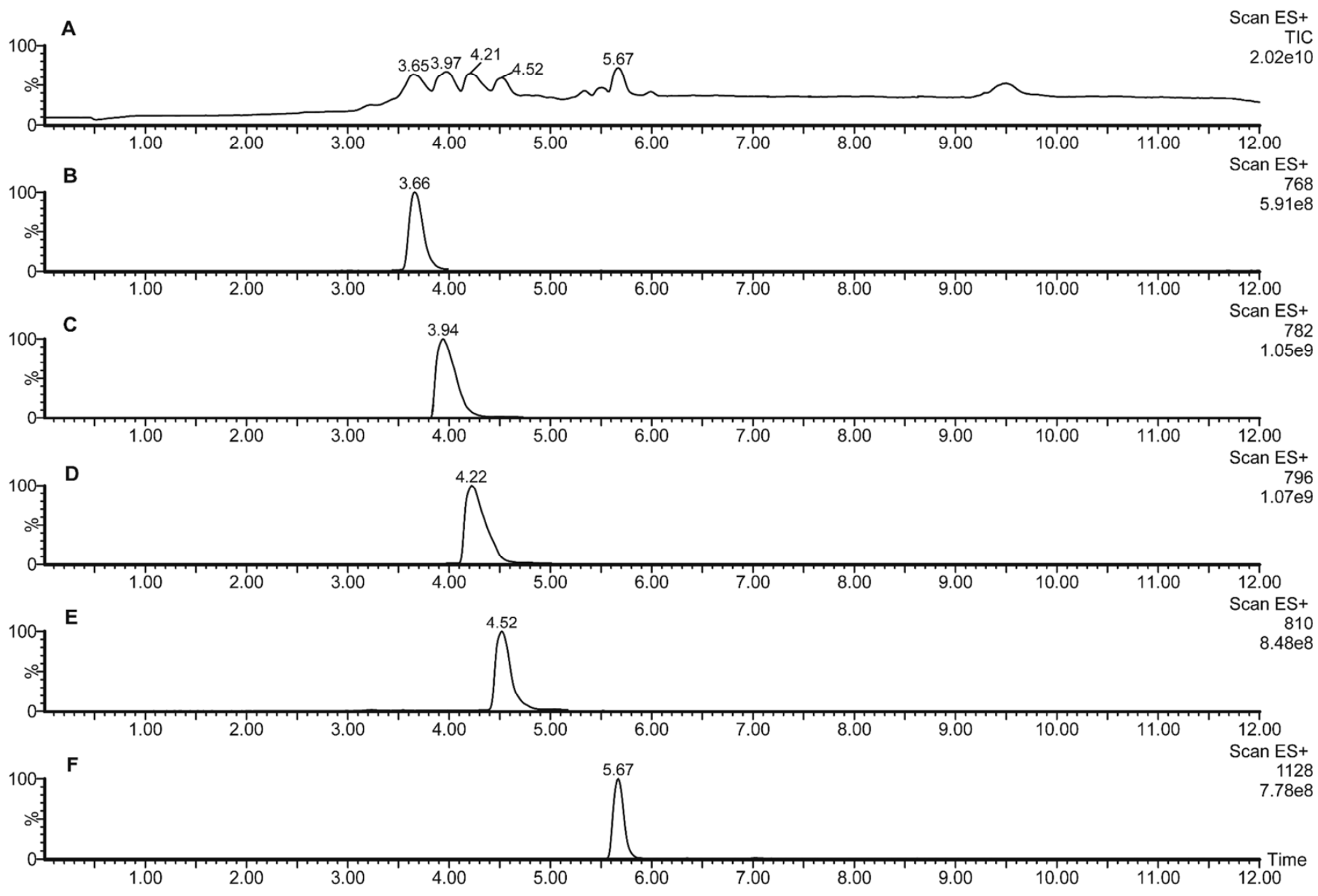

Fig. 3. A, Total ionic current chromatogram of fraction ASBV $-1^{\mathrm{T}}$ and $\mathbf{B}$ to $\mathbf{F}$, extracted ion chromatograms obtained by ultra-high-performance liquid chromatography mass spectrometry for precursor ions of $m / z, 768,782,796,810$, and 1,128 . 
antibiotics known as nonactin, monactin, dinactin, trinactin, and tetranactin (Supplementary Figure 2). An analysis of the HRESIMS spectrum (Table 2; Supplementary Figure 3) and the MS/MS spectrum of a standard nonactin sample (Fig. 4C) confirmed the chemical structures of the compounds.

Similarly, we detected another compound in the higher mass range; it appeared as in ion adducts with $\mathrm{H}^{+}(\mathrm{m} / z, 1,111), \mathrm{Na}^{+}(\mathrm{m} / z$ $1,133), \mathrm{NH}_{4}{ }^{+}(\mathrm{m} / z, 1,128)$, and $\mathrm{K}^{+}(\mathrm{m} / \mathrm{z}, 1,149)$. We submitted an ion of $\mathrm{m} / z, 1,149$ to the CID experiment to identify its chemical structure. The MS/MS spectrum (Fig. 5A) demonstrated successive neutral losses of 99,72 , and $100 \mathrm{u}$; the same pattern arose in an alternate loss. These losses corresponded to valine [Val- $\mathrm{H}_{2} \mathrm{O}$, lactic acid $\left[\mathrm{Lac}-\mathrm{H}_{2} \mathrm{O}\right]$, and 2-hydroxisovaleric acid $\left[\mathrm{Hiv}-\mathrm{H}_{2} \mathrm{O}\right]$ residues, respectively, as reported in the literature $(15,20)$ for the ionophoric cyclodepsipeptide known as valinomycin (Supplementary Figure 4). An analysis of the HRESIMS spectrum (Table 3; Supplementary Figure 5) confirmed the identity of this compound because it helped to determine its exact mass and mo- lecular formula. The MS/MS spectrum of a standard valinomycin sample (Fig. 5B) also aided this identification.

Influence of inorganic salts on the production of bioactive compounds and biomass. Monactin, dinactin, trinactin, tetranactin, and valinomycin production peaked after $7,10,10,15$, and 6 days of incubation, respectively (Fig. 6; data not shown for valinomycin).

Supplementation of PD broth with inorganic salts influenced actinomycete growth and the yield of bioactive compounds. $\mathrm{CuSO}_{4}$ and $\mathrm{FeSO}_{4}$ completely inhibited ASBV $-1^{\mathrm{T}}$ growth, even at the lowest tested dose $(1 \mathrm{mM})$. The other tested salts affected actinomycete growth negatively. $\mathrm{ZnSO}_{4}$ had the strongest inhibitory activity, causing decreases in biomass production of 50 and $75 \%$ at 1 and $5 \mathrm{mM}$, respectively. $\mathrm{MgSO}_{4}$ and $\mathrm{MnSO}_{4}$ reduced actinomycete growth by $\approx 30 \%$. $\mathrm{MnSO}_{4}$ negatively influenced the production of all the monitored compounds, although it affected the valinomycin biosynthetic pathway the least: $\mathrm{MnSO}_{4}$ at a concentration of $5 \mathrm{mM}$ completely inhibited macrotetralide produc-

TABLE 2. High-resolution electrospray ionization mass spectrometry data of macrotetralides identified in the active fraction (Fr ASBV-1) produced by Streptomyces araujoniae ASBV-1 ${ }^{\mathrm{T}}$

\begin{tabular}{lllll}
\hline$m / z(\text { Exp })^{\mathrm{y}}$ & $m / z(\mathrm{Cal})^{\mathrm{z}}$ & Error $(\mathrm{ppm})$ & Molecular formulas & Compounds \\
\hline 773.4463 & 773.4452 & 1.4 & {$\left[\mathrm{C}_{41} \mathrm{H}_{66} \mathrm{O}_{12}+\mathrm{Na}\right]^{+}$} & Monactin \\
789.4201 & 789.4191 & 1.3 & {$\left[\mathrm{C}_{42} \mathrm{H}_{68} \mathrm{O}_{12}+\mathrm{K}\right]^{+}$} & Monactin \\
782.5067 & 782.5055 & 1.5 & {$\left[\mathrm{C}_{42} \mathrm{H}_{68} \mathrm{O}_{12}+\mathrm{NH}_{4}\right]^{+}$} & Dinactin \\
787.4624 & 787.4608 & 2.0 & {$\left[\mathrm{C}_{42} \mathrm{H}_{68} \mathrm{O}_{12}+\mathrm{Na}^{+}\right.$} & \\
803.4362 & 803.4348 & 1.7 & {$\left[\mathrm{C}_{42} \mathrm{H}_{68} \mathrm{O}_{12}+\mathrm{K}\right]^{+}$} & \\
796.5216 & 796.5211 & 0.6 & {$\left[\mathrm{C}_{43} \mathrm{H}_{70} \mathrm{O}_{12}+\mathrm{NH}_{4}\right]^{+}$} & \\
801.4777 & 801.4765 & 1.5 & {$\left[\mathrm{C}_{43} \mathrm{H}_{70} \mathrm{O}_{12}+\mathrm{Na}^{+}\right.$} & \\
817.4513 & 817.4504 & 1.1 & {$\left[\mathrm{C}_{43} \mathrm{H}_{70} \mathrm{O}_{12}+\mathrm{K}^{+}\right.$} & Dinactin \\
810.5380 & 810.5368 & 1.5 & {$\left[\mathrm{C}_{44} \mathrm{H}_{72} \mathrm{O}_{12}+\mathrm{NH}_{4}\right]^{+}$} & Trinactin \\
815.4938 & 815.4921 & 2.1 & {$\left[\mathrm{C}_{44} \mathrm{H}_{72} \mathrm{O}_{12}+\mathrm{Na}\right]^{+}$} & Trinactin \\
831.4674 & 831.4661 & 1.6 & {$\left[\mathrm{C}_{44} \mathrm{H}_{72} \mathrm{O}_{12}+\mathrm{K}\right]^{+}$} & Tetranactin \\
\hline
\end{tabular}

y Ratio $\mathrm{m} / \mathrm{z}$ obtained experimentally.

${ }^{\mathrm{z}}$ Ratio $m / z$ calculated.

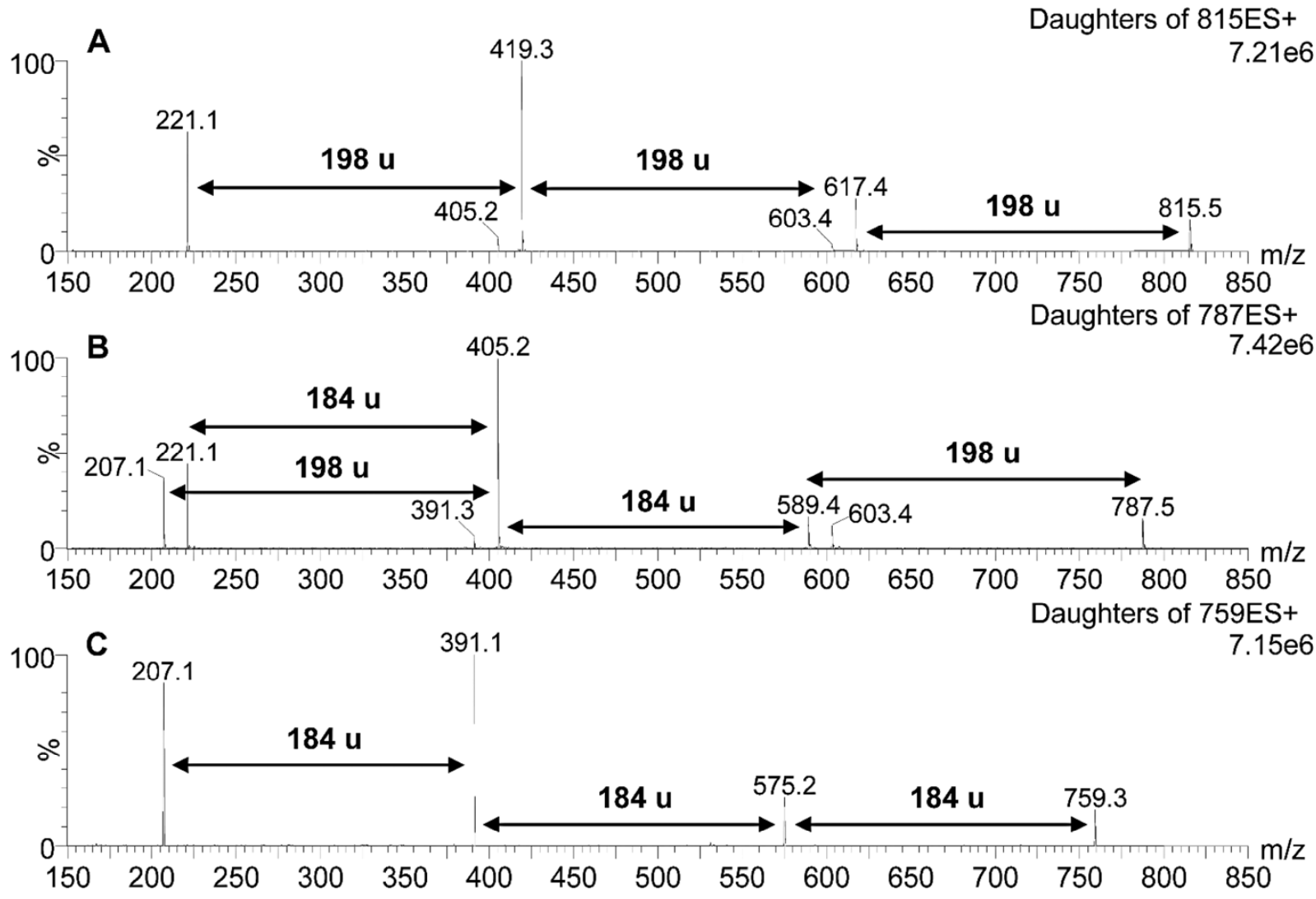

Fig. 4. MS/MS spectra of sodium adducts ions of $\mathbf{A}, \mathrm{m} / \mathrm{z} 787$ and $\mathbf{B}, \mathrm{m} / \mathrm{z} 815$ and of $\mathbf{C}$, the standard nonactin sample of $m / z 759$. 
tion and reduced valinomycin production by $\approx 50 \%$ (Table 4 ). In contrast, $\mathrm{MgSO}_{4}$ enhanced macrotetralide production, which peaked at an $\mathrm{MgSO}_{4}$ concentration of $2 \mathrm{mM}$. A higher $\mathrm{MgSO}_{4}$ dose had a deleterious effect on monactin and dinactin production, and valinomycin production followed a similar pattern. The increases in trinactin and tetranactin were not particularly pronounced, even at the highest $\mathrm{MgSO}_{4}$ dose. Interestingly, $1 \mathrm{mM}$ $\mathrm{ZnSO}_{4}$ completely inhibited macrotetralide synthesis, whereas the valinomycin yield was increased by $116 \%$. At a $\mathrm{ZnSO}_{4}$ concentration of $2 \mathrm{mM}$, valinomycin production diminished, whereas the highest $\mathrm{ZnSO}_{4}$ dose completely inhibited valinomycin biosynthesis.

\section{DISCUSSION}

This study is the first to describe compounds from $S$. araujoniae $\mathrm{ASBV}-1^{\mathrm{T}}$ that are active against $B$. cinerea. Understanding the modes of action of a biocontrol agent is relevant for (i) developing novel strategies that enhance bioactivity, (ii) increasing formulation activity, (iii) establishing screening criteria for selection more effective antagonists, and (iv) meeting the toxi- cological requirements for commercialization $(17,19,26)$. Bacterial secondary metabolites have attracted the attention of both the scientific community and agricultural industries because they are effective against phytopathogenic fungi, present low toxicity, have low production costs, and can be sold at competitive market prices $(1,25)$.

The in vitro assay demonstrated that ASBV $-1^{\mathrm{T}}$ crude extract can efficiently inhibit the germination of $B$. cinerea conidia. The observation that the results obtained with crude extract were equivalent to those obtained with commercial fungicide opens many possibilities for formulations and further commercial applications. For example, the typically prohibitive costs of compound purification could be avoided, at the first instance, by using only the fermented broth as a primary material for formulations. Many microorganisms have been shown to have positive effects against $B$. cinerea infections in strawberry pseudofruit under storage conditions $(11,33,34)$. On the other hand, studies on streptomycetes usually focus on the properties of the antibiotic that inhibit the fungus development. Our attempt to observe the biological control of $B$. cinerea by $S$. araujoniae ASBV $-1^{\mathrm{T}}$ under storage conditions was fruitless, because the isolate did not inhibit

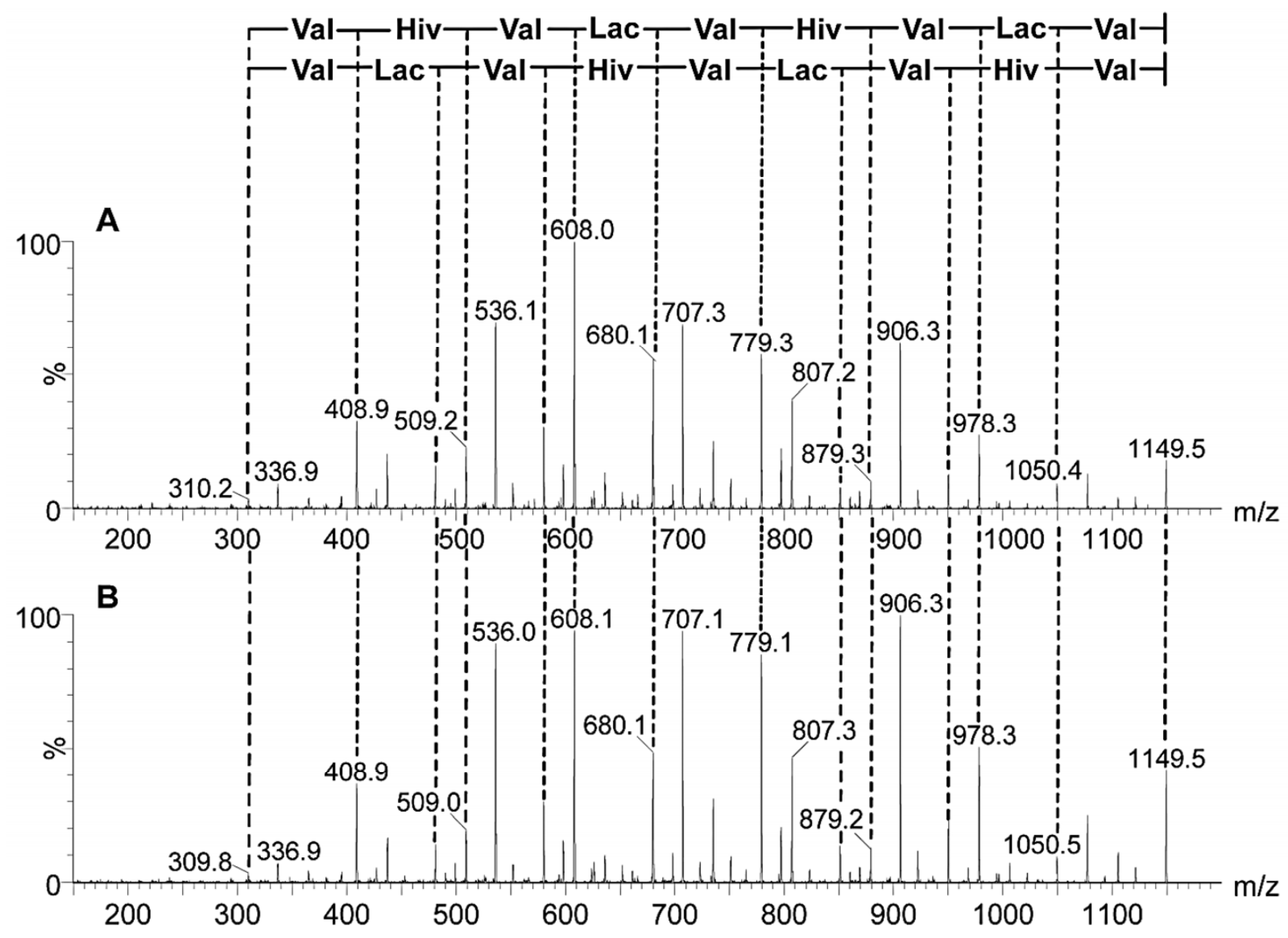

Fig. 5. MS/MS spectrum of A, potassium adduct ion of $m / z 1,149$ present in the fraction Fr ASBV- $1^{\mathrm{T}}$ and $\mathbf{B}$, the standard valinomycin sample of $m / z$, 149 . Val $=$ valine, $L a c=$ lactic acid, and Hiv $=2$-hydroxyisovaleric acid.

TABLE 3. High-resolution electrospray ionization mass spectrometry data of valinomycin identified in the active fraction (Fr ASBV-1) produced by Streptomyces araujoniae ASBV-1 ${ }^{\mathrm{T}}$

\begin{tabular}{|c|c|c|c|c|}
\hline Compound & $m / z(\operatorname{Exp})^{\mathrm{y}}$ & $m / z(\mathrm{Cal})^{\mathrm{z}}$ & Error (ppm) & Molecular formula \\
\hline Valinomycin & $\begin{array}{l}1111.6420 \\
1128.6677 \\
1133.6239 \\
1149.5967\end{array}$ & $\begin{array}{l}1111.6390 \\
1128.6655 \\
1133.6209 \\
1149.5949\end{array}$ & $\begin{array}{l}2.7 \\
1.9 \\
2.6 \\
1.6\end{array}$ & $\begin{array}{l}{\left[\mathrm{C}_{54} \mathrm{H}_{90} \mathrm{~N}_{6} \mathrm{O}_{18}+\mathrm{H}\right]^{+}} \\
{\left[\mathrm{C}_{54} \mathrm{H}_{90} \mathrm{~N}_{6} \mathrm{O}_{18}+\mathrm{NH}_{4}\right]^{+}} \\
{\left[\mathrm{C}_{54} \mathrm{H}_{90} \mathrm{~N}_{6} \mathrm{O}_{18}+\mathrm{Na}^{+}\right.} \\
{\left[\mathrm{C}_{54} \mathrm{H}_{90} \mathrm{~N}_{6} \mathrm{O}_{18}+\mathrm{K}\right]^{+}}\end{array}$ \\
\hline
\end{tabular}

\footnotetext{
${ }^{y}$ Ratio $m / z$ obtained experimentally.
}

${ }^{\mathrm{z}}$ Ratio $m / z$ calculated. 
fungus growth in strawberry pseudofruit. However, this result may have occurred due to the experimental design in which the biocontrol agent and the phytopathogen were inoculated at the same time. In contrast, in the case of peanut grains, the curative treatment inhibited Aspergillus parasiticus germination, although the preventive treatment (A. parasiticus inoculated $24 \mathrm{~h}$ after the isolate ASBV-1 $1^{\mathrm{T}}$ ) showed improved effects (36). However, the bioactive compounds present in the ASBV $-1^{\mathrm{T}}$ crude extract prevented infection with $B$. cinerea at a moderate concentration $\left(100 \mu \mathrm{g} \mathrm{ml}^{-1}\right)$.

The bioassay-guided fractionation and the structural identification of the ASBV- $1^{\mathrm{T}}$ crude extract by MS/MS revealed that two classes of ionophore antibiotics were synthesized by one or more specialized enzymes: nonribosomal peptide synthase and polyketide synthase initiated valinomycin and macrotetralide biosynthesis, respectively. Valinomycin has been reported to act on mitochondrial membrane of $S$. cerevisiae by interfering with $\mathrm{K}^{+}$ permeability (18) and to dissipate the bacterial transmembrane ion gradient, resulting in cytoplasmic leakage (13). Macrotetralides also demonstrate affinity for $\mathrm{Na}^{+}$and $\mathrm{K}^{+}$, with complexation ratios that progressively increase along the homologous series (23). However, further studies are still required to identify the mode of action of valinomycin and macrotetralides against $B$. cinerea. A large number of Streptomyces spp. produce these antibiotics $(24,29)$ and demonstrate activity against bacteria and fungi. However, to the best of our knowledge, this is the first time that both biosynthetic pathways were found to be active in the same streptomycete species. The ASBV $-1^{\mathrm{T}}$ isolate yielded four macrotetralides (monactin, dinactin, trinactin, and tetranactin). We did not detect the biosynthetic precursors nonactic acid, homononactic acid, or nonactin (the first compound in of the macrotetralides series), which indicates that these compounds were completely utilized during the macrotetralides biosynthesis.

Many reports consider macrotetralides as antibiotic mixtures containing dinactin, trinactin and large amounts of tetranactin; these mixtures are known as polynactins (7). According to the literature, tetranactin was assayed against $B$. cinerea and presented a minimum inhibitory concentration (MIC) of $24 \mu \mathrm{g} \mathrm{m} l^{-1}$ (Table 5) (32). Both the in vitro and in vivo analysis of the ASBV $-1^{\mathrm{T}}$ crude extract provided some insights into the antifungal activity of macrotetralides and valinomycin. For example, the MICs of valinomycin and tetranactin were 4 and $24 \mu \mathrm{g} \mathrm{ml}{ }^{-1}$, respectively $(21,35)$; lower values were obtained with the ASBV $-1^{\mathrm{T}}$ crude extract $\left(100 \mu \mathrm{g} \mathrm{ml}^{-1}\right)$. The percentages of monactin, dinactin, trinactin, tetranactin, and valinomycin used in the bioassays were $13,43,32,6$, and $6 \%$, respectively. Therefore, either dinactin or trinactin exerted a lower or nonantagonistic effect against $B$. cinerea; alternatively, the macrotetralides and valinomycin may have interacted nonsynergically. The data obtained from the kinetic analysis of the bioactive compounds may assist in the

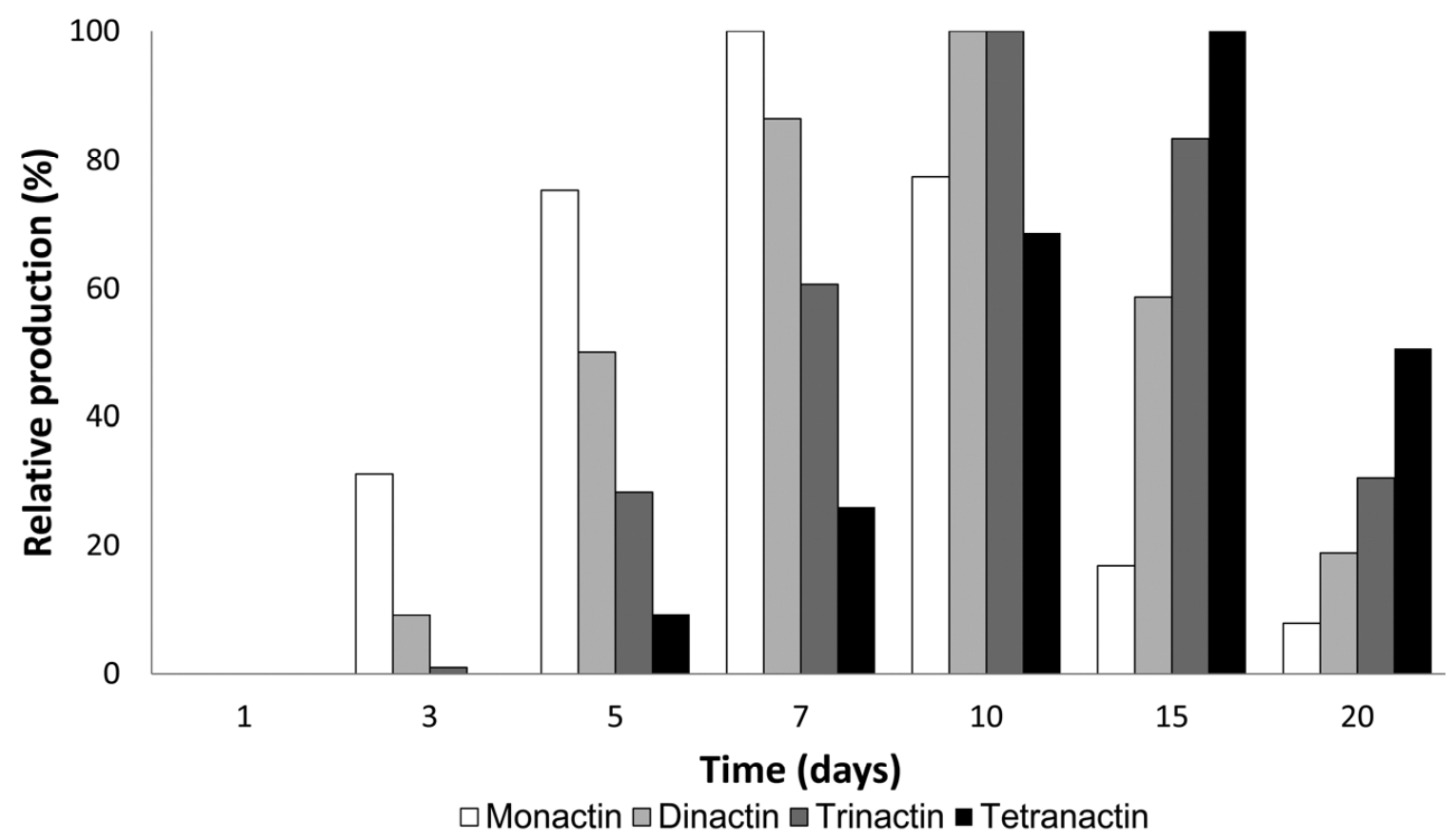

Fig. 6. Kinetics of monactin, dinactin, trinactin, and tetranactin production. Highest production for each compound was considered as maximum production $(100 \%)$ and the other data were obtained relative to this value.

TABLE 4. Effect of supplementation of Streptomyces araujoniae ASBV-1 ${ }^{\mathrm{T}}$ culture with inorganic salts on its production of bioactive compounds ${ }^{\mathrm{Z}}$

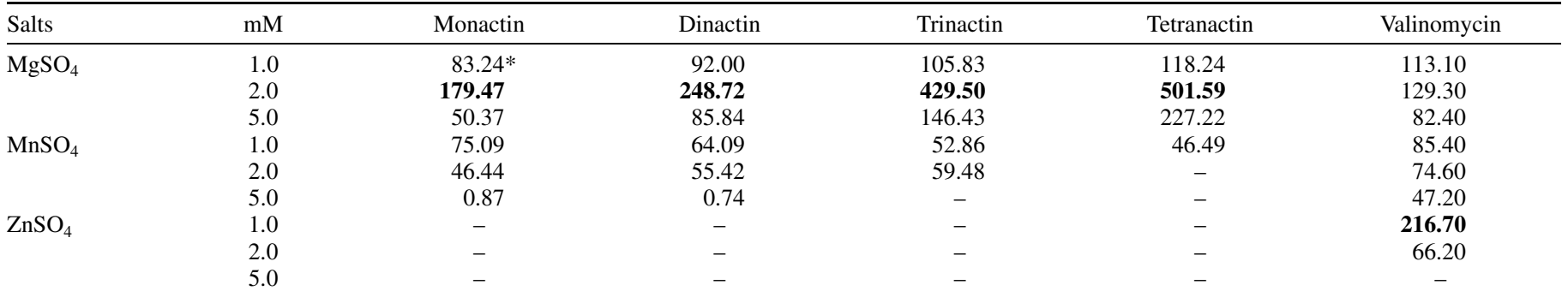

\footnotetext{
${ }^{\mathrm{z}}$ Asterisk (*) indicates percent production value relative to the control (unsupplemented culture), bold indicates highest production values, and - indicates no
} compound production. 
complete separation of all macrotetralides, facilitating the manipulation of actinomycete physiology to produce only the desired compound. For example, the addition of $\mathrm{MnSO}_{4}$ to the culture broth along with a short incubation time and macrotetralide monitoring may increase the probability of extracting the macrotetralides individually. Furthermore, understanding the physiology involved in the production of these antibiotics may enhance the effectiveness of the final formulation.

In summary, we were able to determine which ionophore antibiotics in $S$. araujoniae $\mathrm{ASBV}-1^{\mathrm{T}}$ inhibits $B$. cinerea development. The results are significant because macrotetralides have low toxicity to animals and the environment (7). However, the antitumor characteristics of valinomycin indicate that it is moderately toxic to human health (30). This issue may be overcome by using simple physiological procedures (controlling the salt concentration and incubation time) to reduce valinomycin yield and ensure safer application of the biocontrol agent to strawberry pseudofruit under storage conditions. The positive findings presented here reinforce the previous idea (36) that $S$. araujoniae $\mathrm{ASBV}-1^{\mathrm{T}}$ is a potential biocontrol agent that can mitigate fungal damage to agricultural commodities under postharvest conditions.

\section{ACKNOWLEDGMENTS}

We thank two anonymous referees for reviewing a previous version of this manuscript, Coordenação de Aperfeiçoamento de Pessoal de Nível Superior for providing a fellowship to L. J. Silva, and Fundação de Amparo à Pesquisa do Estado de São Paulo for providing T. D. Zucchi with the fellowship and funding to develop this research (grants 11/14333-6 and 11/50243-1).

\section{LITERATURE CITED}

1. Adams, T. H., and Yu, J. H. 1998. Coordinate control of secondary metabolite production and asexual sporulation in Aspergillus nidulans. Curr. Opin. Microbiol. 1:674-677.

2. Beever, R. E., and Bollard, E. G. 1970. Nature of stimulation of fungal growth by potato extract. J. Gen. Microbiol. 60:273-279.

3. Bérdy, J. 2005. Bioactive microbial metabolites. J. Antibiot. 58:1-26.

4. Canova, S. P., Petta, T., Reyes, L. F., Zucchi, T. D., Moraes, L. A. B., and Melo, I. S. 2010. Characterization of lipopeptides from Paenibacillus sp. (IIRAC30) suppressing Rhizoctonia solani. World J. Microbiol. Biotechnol. 26:2241-2247.

5. Cardoso, R. A., Pires, L. T. A., Zucchi, T. D., Zucchi, F. D., and Zucchi, T. M. A. D. 2010. Mitotic crossing-over induced by two commercial herbicides in diploid strains of the fungus Aspergillus nidulans. Genet. Mol. Res. 9:231-238.

6. Castaño, R., Borrero, C., Trillas, M. I., and Avilés, M. 2013. Selection of biological control agents against tomato Fusarium wilt and evaluation in greenhouse conditions of two selected agents in three growing media. BioControl 58:105-116.

7. Copping, L. G., and Menn, J. J. 2000. Biopesticides: A review of their action, applications and efficacy. Pest Manage. Sci. 56:651-676.

8. Crevelin, E. J., Canova, S. P., Melo, I. S., Zucchi, T. D., Silva, R. E., and Moraes, L. A. B. 2013. Isolation and characterization of phytotoxic compounds produced by Streptomyces sp. AMC 23 from red mangrove (Rhizophora mangle). Appl. Biochem. Biotechnol. 171:1602-1616.

9. Demoz, B. T., and Korsten, L. 2006. Bacillus subtilis attachment, colonization, and survival on avocado flowers and its mode of action on stem-end rot pathogens. Biol. Control 37:68-74.

10. Dotto, M. C., Pombo, M. A., Martínez, G. A., and Civello, P. M. 2011. Heat treatments and expansin gene expression in strawberry fruit. Sci. Hortic. (Amsterdam) 130:775-780.

11. Elad, Y., and Stewart, A. 2007. Microbial Control of Botrytis spp. Pages 223-241 in: Botrytis: Biology, Pathology and Control SE-13. Y. Elad, B. Williamson, P. Tudzynski, and N. Delen, eds. Springer, The Netherlands.

12. Fravel, D. R. 2005. Commercialization and implementation of biocontrol 1. Annu. Rev. Phytopathol. 43:337-359.
13. Gänzle, M. G., and Vogel, R. F. 2003. Studies on the mode of action of reutericyclin. Appl. Environ. Microbiol. 69:1305-1307.

14. Gerhardson, B. 2002. Biological substitutes for pesticides. Trends Biotechnol. 20:338-343.

15. Grese, R. P., Cerny, R. L., and Gross, M. L. 1989. Metal ion-peptide interactions in the gas phase: A tandem mass spectrometry study of alkali metal cationized peptides. J. Am. Chem. Soc. 111:2835-2842.

16. Hernández-Muñoz, P., Almenar, E., Valle, V. Del, Velez, D., and Gavara, R. 2008. Effect of chitosan coating combined with postharvest calcium treatment on strawberry (Fragaria ananassa) quality during refrigerated storage. Food Chem. 110:428-435.

17. Kim, P. I., and Chung, K. C. 2004. Production of an antifungal protein for control of Colletotrichum lagenarium by Bacillus amyloliquefaciens MET0908. FEMS Microbiol. Lett. 234:177-183.

18. Kováč, L., Böhmerová, E., and Butko, P. 1982. Ionophores and intact cells I. Valinomycin and nigericin act preferentially on mitochondria and not on the plasma membrane of Saccharomyces cerevisiae. Biochim. Biophys. Acta Mol. Cell Res. 721:341-348.

19. Medeiros, F. H. V., Martins, S. J., Zucchi, T. D., Melo, I. S. De, Batista, L. R., and Machado, C. 2012. Biological control of mycotoxin-producing molds. Ciênc. Agrotecnol. 36:483-497.

20. Ngoka, L. C. M., and Gross, M. L. 2000. Multistep collisionally activated decomposition in an ion trap for the determination of the amino-acid sequence and gas-phase ion chemistry of lithium-coordinated valinomycin. Int. J. Mass Spectrom. 194:247-259.

21. Park, C. N., Lee, J. M., Lee, D., and Kim, B. S. 2008. Antifungal activity of valinomycin, a peptide antibiotic produced by Streptomyces sp. Strain M10 antagonistic to Botrytis cinerea. J. Microbiol. Biotechnol. 18:880884.

22. Paulitz, T. C., and Bélanger, R. R. 2001. Biological control in greenhouse systems. Annu. Rev. Phytopathol. 39:103-133.

23. Pressman, B. C. 1976. Biological applications of ionophores. Annu. Rev. Biochem. 45:501-530.

24. Řezanka, T., Spížek, J., Přikrylová, V., Prell, A., and Dembitsky, V. M. 2004. Five new derivatives of nonactic and homo-nonactic acids from Streptomyces globisporus. Tetrahedron 60:4781-4787.

25. Saxena, S., and Pandey, A. K. 2001. Microbial metabolites as eco-friendly agrochemicals for the next millennium. Appl. Microbiol. Biotechnol. 55:395-403.

26. Sharma, R. R., Singh, D., and Singh, R. 2009. Biological control of postharvest diseases of fruits and vegetables by microbial antagonists: A review. Biol. Control 50:205-221.

27. Silva, F. de A. S., and Azevedo, C. A. V. 2002. Assistat computational program version for the windows operating system. Rev. Bras. Prod. Agroind. 4:71-78.

28. Silva, L. J., Taketani, R. G., de Melo, I. S., Goodfellow, M., and Zucchi, T. D. 2013. Streptomyces araujoniae sp. nov.: An actinomycete isolated from a potato tubercle. Antonie Leeuwenhoek 103:1235-1244.

29. Solecka, J., Zajko, J., Postek, M., and Rajnisz, A. 2012. Biologically active secondary metabolites from Actinomycetes. Cent. Eur. J. Biol. 7:373-390

30. Teplova, V. V., Mikkola, R., Tonshin, A. A., Saris, N.-E. L., and SalkinojaSalonen, M. S. 2006. The higher toxicity of cereulide relative to valinomycin is due to its higher affinity for potassium at physiological plasma concentration. Toxicol. Appl. Pharmacol. 210:39-46.

31. Vincenti, M., Guglielmetti, G., Andriollo, N., and Cassani, G. 1990. Structural analysis of macrotetralide antibiotic mixtures using collisioninduced dissociation mass spectrometry. Biol. Mass Spectrom. 19:240247.

32. Williamson, B., Tudzynski, B., Tudzynski, P., and Van Kan, J. A. N. A. L. 2007. Botrytis cinerea: The cause of grey mould disease. Mol. Plant Pathol. 8:561-580.

33. Wszelaki, A. L., and Mitcham, E. J. 2003. Effect of combinations of hot water dips, biological control and controlled atmospheres for control of gray mold on harvested strawberries. Postharvest Biol. Technol. 27:255264.

34. Zhang, H., Wang, L., Dong, Y., Jiang, S., Cao, J., and Meng, R. 2007. Postharvest biological control of gray mold decay of strawberry with Rhodotorula glutinis. Biol. Control 40:287-292.

35. Žižka, Z. 1998. Biological effects of macrotetrolide antibiotics and nonactic acids. Folia Microbiol. (Praha) 43:7-14.

36. Zucchi, T. D., Moraes, L. A., and Melo, I. S. 2008. Streptomyces sp. ASBV-1 reduces aflatoxin accumulation by Aspergillus parasiticus in peanut grains. J. Appl. Microbiol. 105:2153-2160. 